\title{
Foreign body ingestion in children: an audit of transit time
}

Diana Macgregor, James Ferguson

\begin{abstract}
Objectives-To study the pattern of ingestion of radio-opaque foreign bodies in children and to ascertain the average transit time to passage per rectum in order to rationalise future management. Methods-This prospective study consisted of 100 children under the age of 14 years, presenting to the accident and emergency department of the Royal Aberdeen Children's Hospital having ingested a radio-opaque foreign body. All children had initial radiography and were subsequently followed up in an attempt to ascertain the transit time of the foreign body.

Results-The majority of ingestions (73\%) were in younger children ( 5 years and under). The time taken to pass the foreign bodies per rectum varied greatly. Almost half were never recovered. Transit time appears to increase with age. Three children were given oral cisapride to increase gastric motility after prolonged retention in the stomach.

Conclusions-Transit time is very variable and cannot be predicted. Sifting of the stools is unpleasant and unhelpful. Repeat radiography should not be encouraged as this results in unnecessary radiation. Cisapride may be useful in cases where there is prolonged retention of a foreign body in the stomach. There may be an indication for routine use of cisapride in all cases of ingested foreign bodies, however further audit would be required.

(F Accid Emerg Med 1998;15:371-373)
\end{abstract}

Keywords: foreign bodies; children; transit time

Accidental ingestion of foreign bodies is common in children of all ages. Once in the stomach problems are $\operatorname{rare}^{12}$ and the vast majority are passed per rectum. However marked parental anxiety is commonplace, particularly after the ingestion of large objects by small children. Previously, serial radiographs have been recommended to monitor progress and to ensure passage of the foreign body. In addition parents have been requested to sift the stools, which frequently results in increased anxiety if the foreign body is not identified.

\section{Methods}

The study was undertaken in the Royal Aberdeen Children's Hospital, which has the only paediatric accident and emergency (A\&E) department in the north east of Scotland, serv- ing a catchment area of half a million people. The department sees 19000 new cases per year, all children under the age of 14 years.

The study ran from November 1994 to June 1996 when 100 children had been entered. Non-radio-opaque foreign bodies were excluded from the study as was any child with a history of previous abdominal surgery such as pyloroplasty. Ingested button batteries were also excluded, as these require prompt removal. When a child presented to the $A \& E$ department having possibly ingested a radioopaque foreign body, an initial single radiograph encompassing neck, chest, and upper abdomen was undertaken to exclude lodgement of the foreign body in the oesophagus.

Having ascertained that the foreign body was in the stomach, the child was entered into the study, their details being noted on a specially designed form. The parents were advised that the foreign body should be passed per rectum within 10-14 days. They were provided with disposable gloves and advised to sift all stools with an old fork and note the date when the foreign body was passed. The parents were contacted by telephone two weeks later. If no foreign body had been retrieved at that time

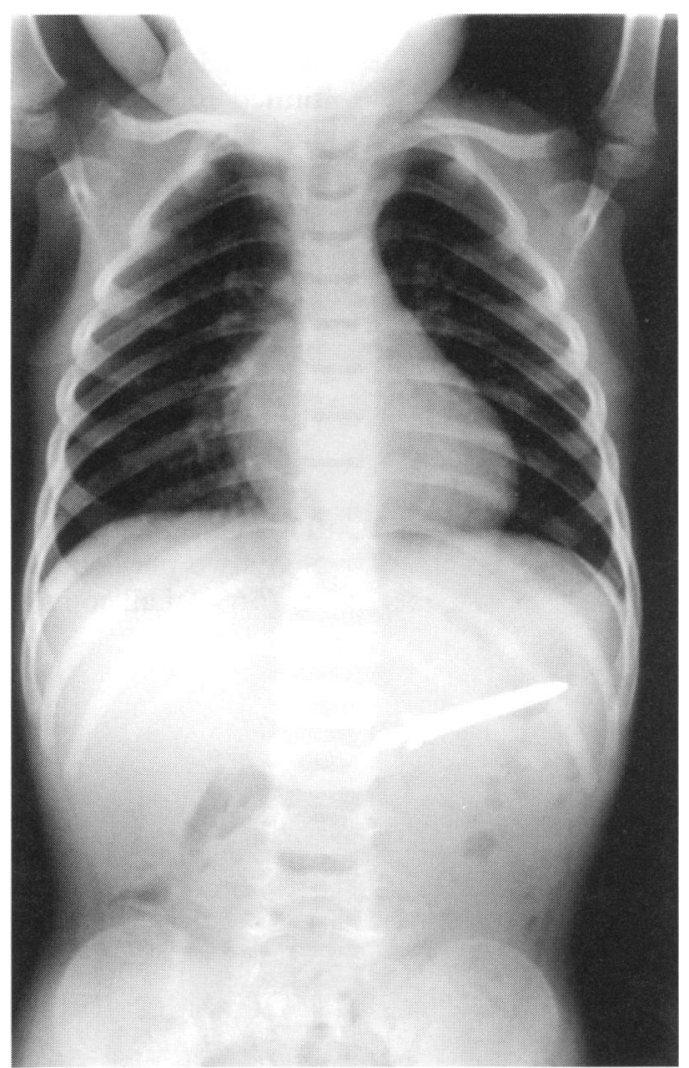

Figure 1 Nailfile shaped like a bag of golf clubs found in one child. 


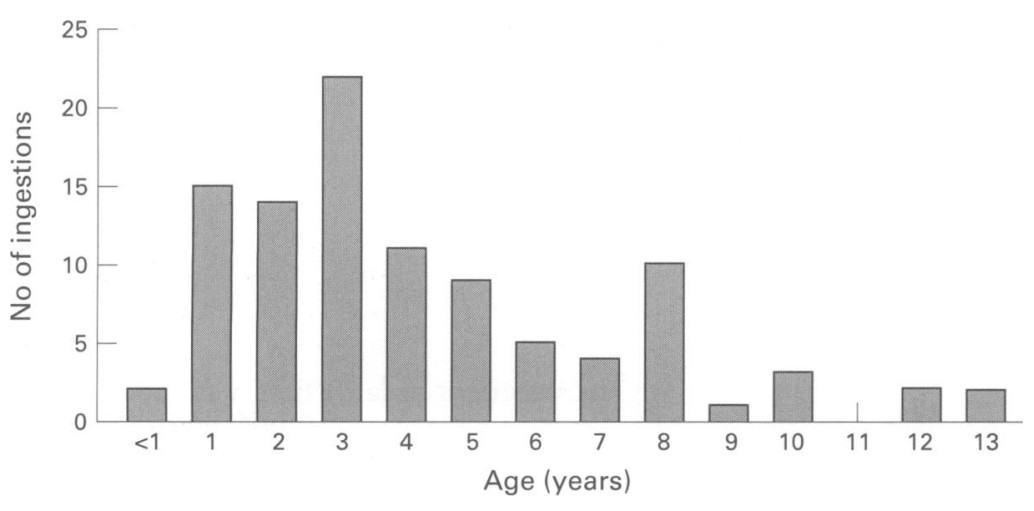

Figure 2 Number of ingestions a year by age.

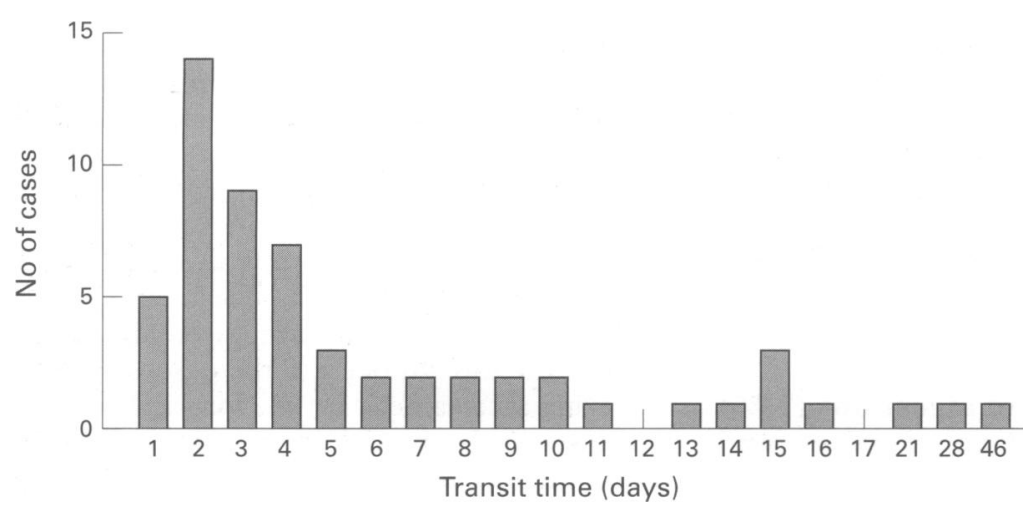

Figure 3 Transit time for each case.

they were advised to continue checking and were contacted again at weekly intervals. No foreign body had been found at three weeks after ingestion in 17 of the first 51 children entered into the study. These children had repeat radiography at this point and 13 of the 17 radiographs showed that the foreign body was absent and had been passed unnoticed. Routinely repeating radiography was discontinued for the subsequent 49 cases as it was thought to expose the child to unnecessary radiation. Thereafter if the foreign body had not been retrieved after four weeks, and the child was asymptomatic, it was assumed to have been passed unnoticed.

There were a small number of children who had repeat radiography due to persistent parental anxiety despite explanation of the risks of radiation. All were negative.

\section{Results}

The objects ingested were extremely varied. Sixty two per cent were coins, with the majority (56\% of all coins) being small coins ( $1 \mathrm{p}$ and

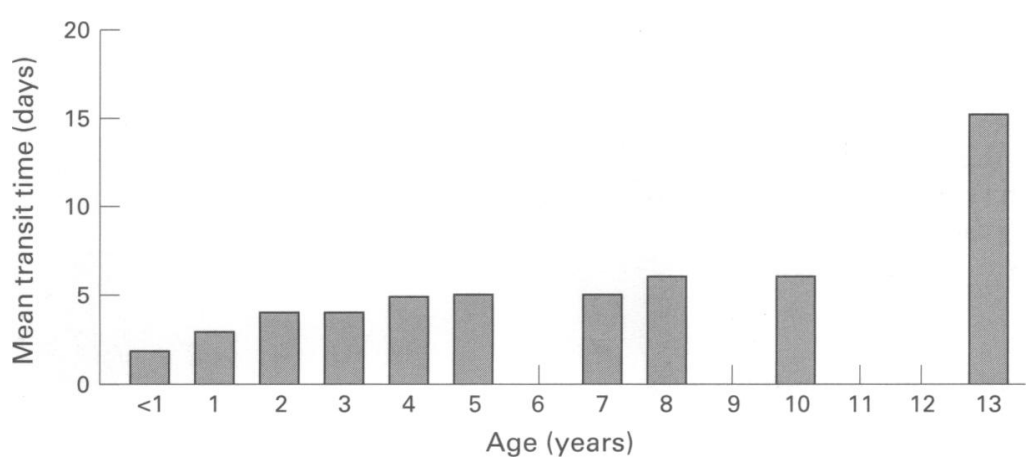

Figure 4 Mean transit time by age.
$5 p$ ); this mirrors other studies. ${ }^{34}$ Other objects included ball bearings, pins, marbles, screws, buttons, drawing pins, a clothes peg spring, a light bulb, and a nailfile shaped in the form of a bag of golf clubs (fig 1)!

The age of the children included in the study ranged from 9 months to 13 years; $73 \%$ were under 6 years of age and the median age was 3 years (fig 2).

During the study period no cases of oesophageal impaction were identified. This is in contrast to other studies when up to $82 \%$ of foreign bodies were found to be impacted in the oesophagus. ${ }^{5}$

Of the 100 foreign bodies proved to have been ingested, 58 were retrieved leaving 42 which were not found after four weeks and so presumed to have passed unnoticed. In the group where the foreign body was retrieved, transit time varied from one to 46 days $(60 \%$ were passed by four days, $83 \%$ by 10 days, and $93 \%$ by 15 days). Median time of passage was six days (fig 3 ). It would appear that the mean transit time of an ingested foreign body increases with age (fig 4), although numbers are small. The retrieval rate did not vary with age.

Seventeen children had repeat radiography. A foreign body was shown to be persistently present in the stomach in four cases despite absence of symptoms.

Three of these children (at 16, 21, and 28 days respectively) were given cisapride suspension $(5 \mathrm{mg} / \mathrm{ml}$ ) at a dose of $0.2 \mathrm{mg} / \mathrm{kg}$ four times over 24 hours. All three children passed the foreign body within 24 hours of starting cisapride. Due to an oversight the fourth child was referred to the paediatric surgeons. Repeat radiography showed that a coin was still present in the stomach 46 days after ingestion. Admission for endoscopic removal was arranged but check radiography on admission 23 days later (69 days after ingestion) showed that the coin had been passed unnoticed in the intervening period.

\section{Discussion}

Ingestion of foreign bodies by children is common and generates a great deal of parental anxiety and a significant workload for the $A \& E$ department. While protocols have been proposed for the management of such children, ${ }^{6}$ it was felt that advice for parents should be based on reliable evidence rather than established practice, which may be contributing to parental anxiety and resulting in unnecessary radiology with increased exposure and cost.

It has been suggested that metal detectors may contribute to the diagnosis and management of ingested metallic foreign bodies, ${ }^{78}$ but these are unable to discriminate between a foreign body in the stomach or one impacted just above the cardia. However metal detectors are useful for detection of ingested aluminium ring pulls which may be difficult to identify on radiography ${ }^{9}$ and could also be used to verify if a foreign body had subsequently been eliminated. This may avoid repeat radiography. ${ }^{10}$

None of our sample group had a foreign body impacted in the oesophagus at presentation on initial radiography. It is essential to 
undertake routine radiography of the neck, chest, and upper abdomen on presentation to exclude impacted foreign bodies, however, as several cases of erosion with catastrophic effects have been reported. These may be asymptomatic $^{11}$ and result in late oesophageal perforation $^{12}$ or stricture. ${ }^{13}$ Sudden death has been reported despite a prolonged asymptomatic period. ${ }^{14}$

There were no cases of obstruction, unlike other studies, which demonstrated only $80 \%$ being eliminated uneventfully. ${ }^{2}$ Transit time of ingested foreign bodies appears to vary greatly and no accurate estimate can be made.

Sifting stools is an unpleasant task and so frequently is not performed efficiently. Forty two per cent of the foreign bodies were not retrieved despite parents sifting the stools. It was thought that this would be more prevalent in older children who went to the toilet independently but this was not the case. It would seem that sifting stools is a futile practice, which only contributes to parental anxiety when the object is not identified and the child remains asymptomatic.

No child in the study returned due to symptomatology. However in the early stages of the study four children were identified who had retention of the foreign body in the stomach for a prolonged period of time. All responded to conservative measures, although the potential for erosion, albeit unlikely, still exists.

Cisapride at a dose of $0.2 \mathrm{mg} / \mathrm{kg}$ four times over 24 hours is a quick, cheap, and effective way of encouraging the passage of a foreign body out of the stomach. This raises the possibility of giving a 24 hour course of cisapride to all children who have been proved to have a foreign body in the stomach; this would possibly encourage prompt passage of foreign bodies without resort to repeat radiography. This may prove to be an acceptable practical method of dealing with the problem.

No ethical approval was sought for this study, as it was non-invasive. Ethical approval is being sought for a further study using cisapride routinely.

\section{Conclusion}

Transit time of ingested foreign bodies is variable. Sifting of stools is unpleasant and inaccurate and we recommend that this is actively discouraged unless the foreign body is valuable! Cisapride is a useful adjunct and perhaps could be used more frequently.

Advice to parents should include information discouraging attempted retrieval of the foreign body unless it is of value. Such written advice should emphasise returning to the $A \& E$ department immediately if the child develops any symptomatology or abdominal pain.

1 Jain A, Gupta M, Sharma P, et al. Swallowed sharp foreign bodies (sewing needles): a conservative approach. Indian Med Sci 1994;48:261-3.

2 Sheu BS, Shin JS, Chen KW, et al. Endoscopic removal of a large intragastric foreign body with an overtube-a case report. Chin Med J (Engl) 1994;54:193-7.

3 Paul RI, Christoffel KK, Binns HJ, et al. Foreign body ingestions in children: risk of complication varies with site of initial health care contact. Pediatric Practice Research of initial health care contact. Ped.

4 Reilly JS, Walter MA. Consumer product aspiration and ingestion in children: analysis of emergency room reports to the National Electronic Injury Surveillance System. Ann Otol Rhinol Laryngol 1992;101:739-41.

5 Lehmann CU, Elitsur Y. Keep the change doc-coins in the upper GI tract of children. W V Med J 1995;91:13-5.

6 Stringer MD, Capps SNJ. Rationalising the management of swallowed coins in children. BMJ 1991;302:1321-2.

7 Tidey B, Price GJ. The use of a metal detector to locate ingested metallic foreign bodies in children. J Accid Emerg Med 1996;13:341-2.

8 Sacchetti A, Carraccio C, Lichenstein R. Hand held metal detector identification of ingested foreign bodies. Pediat Emerg Care 1994;10:204-7.

9 Bradburn DM, Carr HF. Radiographs and aluminium-a pitfall for the unwary. BMJ 1994;308:1226.

10 Ros SP, Cetta F. Metal detectors-an alternative approach to the evaluation of coin ingestions in children. Pediatr Emerg Care 1992;8:134-61.

11 Conners GP, Chamberlain JM, Ochsenschlager DW. Symptoms and spontaneous passage of esophoegeal coins. Arch Pediatr Adolesc Med 1995;149:36-9.

12 Tucker JG, Kim HH, Lucas GW. Oesophageal perforation caused by coin ingestion. South Med J 1994;87:269-72.

13 Doolin EJ. Esophageal stricture: an uncommon complication of foreign bodies. Ann Otol Rhinol Laryngol 1993;102:863-6.

14 Byard RW. Mechanisms of unexpected death in infants and young children following foreign body ingestion. J Forensic 